\title{
Posterior lumbar interbody fusion in the treatment of symptomatic spinal stenosis
}

\author{
Domagoj Coric, M.D., and Charles L. Branch, Jr., M.D. \\ Department of Neurosurgery, Bowman Gray School of Medicine of Wake Forest University, \\ Winston-Salem, North Carolina
}

Lumbar spinal stenosis is often the result of advanced degeneration of motion segments of the lumbar spine. Loss of disc height, facet displacement and hypertrophy, spondylosis, and spondylolisthesis, as well as buckling of the ligamentum flavum and annulus fibrosus, all contribute to impingement on the spinal canal and intervertebral foramen in lumbar stenosis. There is a subgroup of patients with spinal stenosis in whom the spine is unstable preoperatively or becomes destabilized following decompression who would benefit from an initial fusion procedure. Posterior lumbar interbody fusion (PLIF) addresses several aspects of the multifactorial pathophysiology responsible for spinal stenosis and may arrest the degenerative changes at the fused level. Fusion, in particular PLIF, should be considered in complex cases of lumbar spinal stenosis, most notably in patients with postlaminectomy stenosis or stenosis associated with spondylolisthesis.

Key Words * posterior lumbar interbody fusion * lumbar spinal stenosis * spondylolisthesis * fusion

Spinal stenosis and herniated nucleus pulposus are among the most common degenerative conditions of the lumbar spine. Spinal stenosis is the most common diagnosis associated with lumbar spine surgery in persons older than 65 years of age.[2,17] Unlike radiculopathy secondary to herniated nucleus pulposus, lumbar spinal stenosis is not a distinct diagnostic entity. Both the pathological anatomy leading to spinal stenosis and the clinical symptoms that are manifested by the disease process are heterogeneous. Lumbar stenosis encompasses diverse abnormalities that culminate in narrowing of the central spinal canal, lateral canals, recesses, or intervertebral foramen.[3,31] The disease may be local, segmental, or generalized and may consist of decreased disc space height and protrusion of annulus fibrosus, hypertrophic osteoarthritic changes in the inferior or superior facets, osteophyte formation, ligamentum flavum buckling or hypertrophy, or various combinations of these factors leading to entrapment or compression of neural structures.[2,3,25,43,63] Lumbar stenosis has been classified anatomically as central or lateral (or mixed) and developmentally as congenital or acquired. Central stenosis involves narrowing predominantly of the spinal canal.[3,19,41,43,63] Lateral stenosis has been subdivided as entrance zone stenosis, mid-zone stenosis, and exit zone stenosis.[43] Lateral stenosis has also been referred to as lateral recess, foraminal canal, subarticular, subpedicular, intervertebral foramen, and 
lateral gutter stenosis.[43,59] Congenital stenosis may be idiopathic or due to achondroplasia.[1] Acquired stenosis is subdivided into degenerative, spondylolisthetic, spondylotic, postlaminectomy, postfusion, posttraumatic, and metabolic stenosis.[3,11] An eclectic group of clinical symptoms have commonly been attributed to stenosis including: postural pain; aching and cramping of the lower extremities; neurogenic claudication; back pain; unilateral or bilateral radiculopathy; and morning stiffness. Lower-extremity numbness and paresthesias, as well as neurological deficit including reflex loss, motor weakness, sphincter disturbance, and muscle atrophy may also be part of the clinical presentation.[3,11,19,23,26,31,41,63]

\section{ANATOMICAL CHARACTERISTICS}

The vertebral bodies and discs account for the majority of the axial load bearing capability of the spine. The disc absorbs load and stress, provides support, and resists movement. The superior facet and associated ligamentum flavum form the roof of the lateral recess, where nerve roots exit the canal and enter the foramen. The lumbar facet complex is biplanar with the medial portion oriented in the coronal plane and the lateral portion in the sagittal plane. The medial portion (coronal) limits forward translation and the lateral portion (sagittal) resists lateral rotation.[30,62,72] Therefore, the total facet load consists of a component responsible for sharing axial load bearing with the disc as well as components for resisting anterior and lateral shear.[54] Ligaments play a primary role in resisting flexion rotation and posterior shear.[62] Biomechanical studies on cadavers demonstrate that the posterior ligaments, notably the supraspinous and interspinous ligaments, exert a significant effect on tensile stiffness.[4]

The neural foramen is bordered by the superior and inferior articular processes and pars interarticularis of the superior vertebra dorsally, sequential pedicles superiorly and inferiorly, and the intervertebral disc and the posterolateral surface of the vertebral body ventrally. The nerve root exists caudal to the pedicle, and the dorsal root ganglion lies in the superior and lateral portion of the foramen.[25,41,59]

\section{PATHOLOGICAL CHARACTERISTICS}

Degenerative lumbar spinal stenosis is the end result of a cascade of progressive changes that inevitably result in a reduction of spinal canal and/or neuroforaminal volume.[38,41,59,74] A motion segment or functional spine unit consists of two adjacent vertebral bodies, the intervertebral disc, associated ligaments, and facet joints.[55] The ligaments, facets, and disc stabilize the motion segment. Certain configurations, or damage to any of these stabilizing structures, place additional stress on the remaining structures.[41,62,75] Increased sagittal orientation of the facets has been correlated with degenerative spondylolisthesis and lateral stenosis.[24,58,62] Removal of a part of the medial facet during standard hemifacetectomy reduces the resistance to forward (sagittal) translation leading to postdecompression spondylolisthesis.[24,30,47] The ability of the normal intervertebral disc to resist substantial axial stresses decreases with the aging process. Over time, there is a decrease in intradiscal water concentration and a concomitant increase in fibrous tissue concentration. The disc becomes desiccated, and ultimately there is loss of the ability of the nucleus pulposus to evenly redistribute biomechanical loads.[33] This condition ultimately leads to internal disc disruption, disc resorption, annular buckling, and formation of bridging osteophytes.[6,33] As the load-bearing capacity of the disc degenerates there is loss of disc height, which leads to facet displacement and may, ultimately, result in segmental instability. The decreased disc space height may result in nerve root impingement by caudal migration of the superior pedicle. The shape of the intervertebral foramen is also altered by disc degeneration. Anatomical studies on cadavers demonstrate that disc collapse significantly reduces the diameter of the 
foramen.[14,25,59] Increased stresses lead to reactive thickening of the lamina and hypertrophy of the ligamentum flavum, further reducing canal and foramen diameter.[33,75] Increased load and instability lead to pathological changes in the facet joints including: degeneration of the synovium and articular cartilage; fracture of the articular processes; laxity of the joint capsule; and osteophyte formation.[41] Excessive facet hypertrophy and osteophyte formation impinge on the spinal canal and lateral recess. Primary enlargement of the inferior facet and lamina narrows the central canal. Enlargement of the superior facet causes encroachment of the lateral recess and intervertebral foramen.[25,33,43,63]

It is evident that decompressive lumbar surgery plays a significant role in destabilizing the spine in a subgroup of patients with stenosis.[10,28,32,50] Surgical removal of the posterior elements during decompressive laminectomy or hemilaminectomy places additional load on the disc and may accelerate degeneration. $[4,30,47,51]$ Postoperative progressive slippage as a result of segmental instability often leads to recurrent symptomatic spinal stenosis.[26] Brodsky[10] evaluated a series of 552 patients with lumbar stenosis and determined that nearly half $(41 \%)$ had undergone previous laminectomy or fusion procedures. Cauchoix and associates[12] reported that additional spondylolisthesis and spinal instability are complications of decompression for stenosis caused by degenerative spondylolisthesis, and they recommended fusion for that condition. Tile, et al.,[67] reported that all of their patients with spondylolisthesis developed progressive slippage postoperatively. Shenkin and Hash[64] followed 59 patients after multiple-level bilateral laminectomies and facetectomies and reported that $15 \%$ of patients in whom three or more levels were removed developed progressive spondylolisthesis. Robertson, et al.,[58] reported that $58 \%$ of 33 patients treated by means of decompressive laminectomy showed postoperative spondylolisthesis of greater than 5\% within 1 year of surgery. In 1990, Iida and associates[32] evaluated 46 patients who had undergone decompressive laminectomy for spinal stenosis and on follow-up examination confirmed instability at the operated level, adjacent level, or both in $83 \%$ of that group. Herkowitz and Kurz[26] reported spondylolisthetic progression in $96 \%$ of patients treated by decompression alone. Recently, Fox and colleagues[22] retrospectively studied 124 patients with degenerative lumbar stenosis treated with and without fusion; they reported progressive postoperative spondylolisthesis in $31 \%$ of patients with normal preoperative alignment and in $73 \%$ of patients with preoperative subluxation treated without fusion.

\section{TREATMENT OPTIONS}

There have been no randomized trials comparing surgical with nonsurgical therapy in patients with spinal stenosis, but nonsurgical treatment is notoriously ineffective in relieving the severe symptoms of lumbar stenosis.[5,35,73] A conventional operative treatment for central spinal stenosis is wide decompression of the affected neural structures. Traditionally, this has entailed a total laminectomy at the involved segment(s) with varying degrees of facetectomy and/or foraminotomy.[2,3,19,23,27,29,40,45,51,53,54,63,68-70] A more limited interlaminar decompression with medial facetectomy has been advocated for lateral stenosis without a significant central component.[43,45,57,64] Decompressive surgery alone does not address the underlying degenerative process responsible for creating the stenosis and, in some circumstances, may serve to accelerate it. $[9,10,26,28-30,32,36,42,51,57,65]$ The ideal surgical intervention would remove only the bone and ligament needed to free compressed neural elements while preserving spinal stability without contributing to the degenerative process. When this is impossible or impractical, the corrective surgical procedure should decompress the neural elements while reducing the impact of the existing degenerative changes. Improving body mechanics and muscular conditioning may slow the degenerative process, but ultimately elimination of the motion segment may be necessary. At this point, segmental arthrodesis 
should be considered.

\section{POSTERIOR LUMBAR INTERBODY FUSION}

Posterior lumbar interbody fusion (PLIF) allows for decompression of the neural elements while preserving certain components of the posterior supporting structures, including the spinous processes and interspinous ligaments, and accomplishing fusion of the motion segment. The neural elements are decompressed through bilateral laminotomies and medial facetectomies. The nerve roots are visualized and freed of any adhesions in preparation for the total discectomy. The near-total discectomy facilitates the placement of substantial interbody graft and minimizes the risk of recurrent stenosis by bulging annulus or recurrent disc herniation. The interbody graft restores disc space height (Fig. 1) and the normal anatomical configuration of the neural elements and the motion segment.[7,8,13,16,44,46]

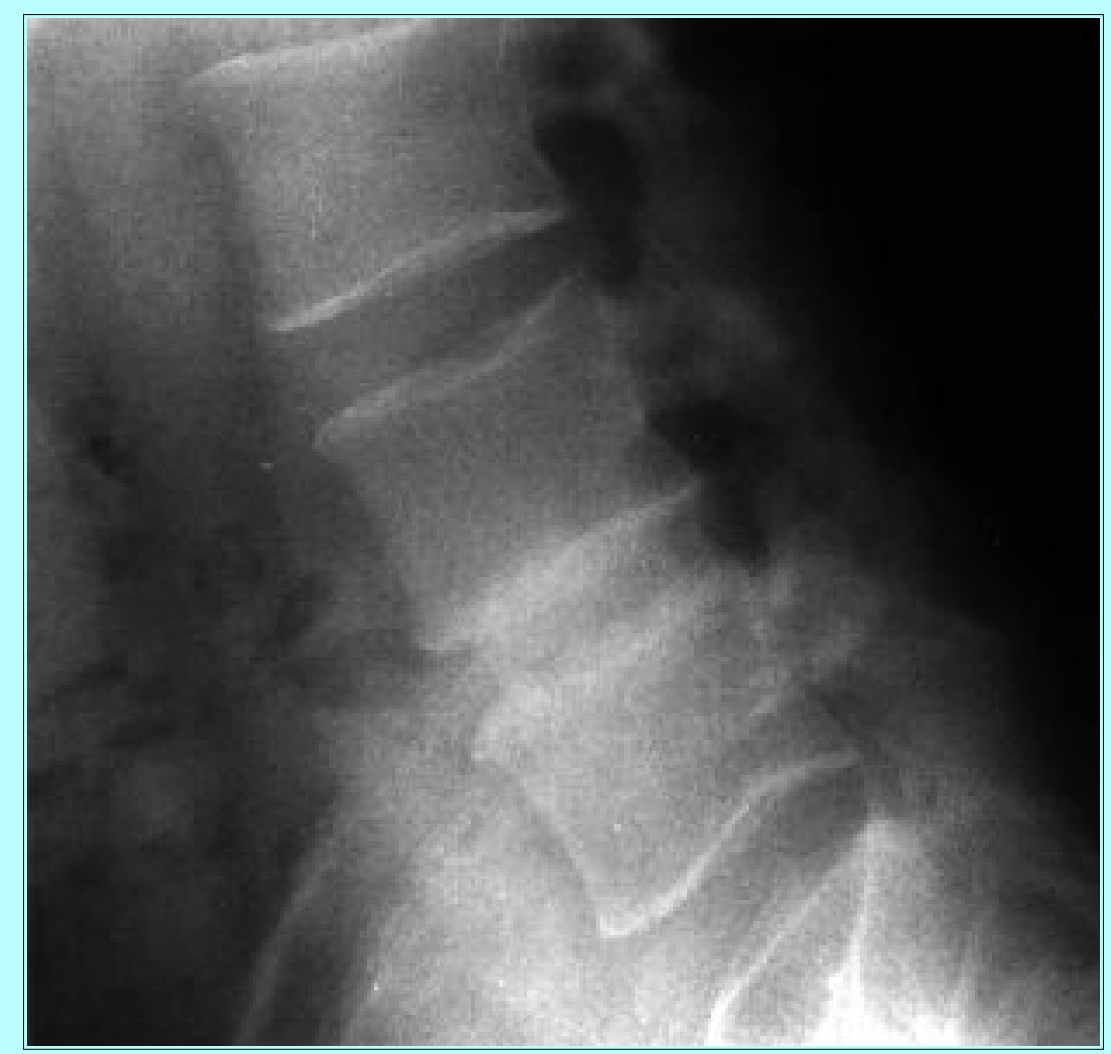

Fig. 1. Plain lateral lumbar radiograph obtained 9 months postoperatively, demonstrating solid osseous fusion of an allograft PLIF at L4-5. Note the maintenance of disc space height and foraminal area in relation to the normal adjacent levels.

In fact, PLIF restores all the anatomical properties of the functional spinal unit with the exception of motion. Cadaveric studies demonstrate a significant increase in foraminal area with distraction of the disc space.[59] The restoration of the disc space height ameliorates impingement on the nerve root by the pedicle and reconstitutes the neural foramen. Correction of forward slippage in degenerative spondylolisthesis is possible with PLIF (Fig. 2). Successful interbody arthrodesis stabilizes the motion segment, eliminating pathological motion, and arresting further spondylolisthesis.[20,31,46,60] It is well recognized that lateral intertransverse process fusion does not reliably fuse the segment or prevent progression of spondylolisthesis. $[9,29,37,42,73]$ Furthermore, there have been reports of persistent back pain despite intact posterolateral fusion.[71] Posterior lumbar interbody fusion minimizes the risk of recalcitrant pain in such cases of internal disc disruption or discogenic pain. 


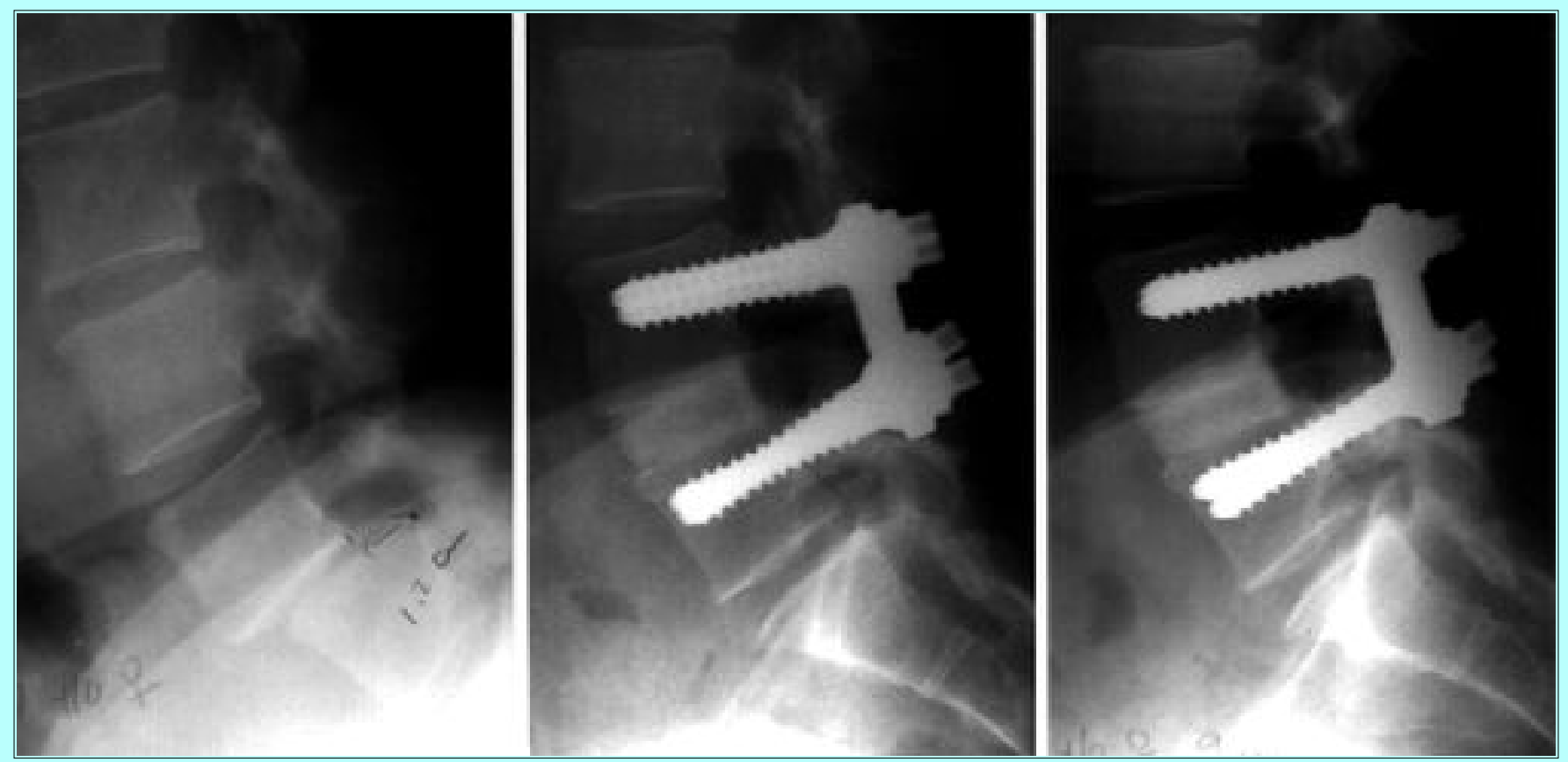

Fig. 2. Plain lateral lumbar radiograph demonstrating a postlaminectomy spondylolisthesis at L4-5 in a 65-year-old woman (left). Postoperative radiographs at 3- (middle) and 9-month follow-up (right) examinations show reduction of spondylolisthesis with transpedicular fixation and solid interbody fusion.

Because the graft is placed under compression, enhancing primary bone healing, PLIF is a biomechanically superior fusion technique. $[6,13,44]$ Summation of loading is greatest at the lowest lumbar segments where $80 \%$ of weight bearing stress occurs across the interbody space. $[8,13,60]$ Theoretically, because PLIF provides a load-bearing graft, the procedure should result in superior fusion rates that can be further augmented by posterior fixation through the same exposure. Posterior lumbar interbody fusion provides the graft with a wide area of bone surface contact and a copious blood supply, as well as placing the anterior and posterior ligaments in tension. $[6,13,46]$ The documented risk of recurrent stenosis caused by bone overgrowth of a posterior fusion mass is avoided with the interbody graft.[56]

Decompressive laminectomy deals with one symptomatic aspect of the complex disease process leading to lumbar stenosis. This procedure is designed simply to relieve neural compression without regard to the underlying pathophysiological mechanisms responsible for creating the condition and, in the process, may serve to exacerbate the underlying disease. However, PLIF allows for neural decompression while addressing a number of the multifactorial causes of stenosis including pathological changes in the disc space and facet complexes. Furthermore, successful interbody fusion directly treats the common symptom of back pain associated with segmental instability originating from the disc and facets as well as providing prophylaxis against future instability and spondylolisthesis. It is apparent that PLIF, unlike decompressive laminectomy, does not contribute to the degenerative cascade in lumbar stenosis and may serve to arrest this process; this supposition has been supported by limited reports of clinical experience. Lin, et al.,[46] reported a 74\% satisfactory clinical result and a 93\% fusion rate in 71 patients with spinal stenosis treated with PLIF. Hutter[31] reviewed 142 patients with spinal stenosis treated with PLIF and obtained good or excellent results in $78 \%$ as well as a $91 \%$ fusion rate.

Technical innovations, including specialized instruments and graft materials, continue to decrease the operative morbidity rates and time associated with PLIF. The use of allograft bone avoids the significant 
morbidity and time associated with autograft harvest. Newer interbody devices, including the recently Federal Drug Administration-approved threaded titanium cage constructs, offer the advantages of relative ease of application and increased rigidity (Fig. 3). Long-term follow-up review is necessary to confirm the early promise of these new interbody devices, especially regarding pseudarthrosis rates and the potential of stress shielding of the graft inside the stiff cage construct.

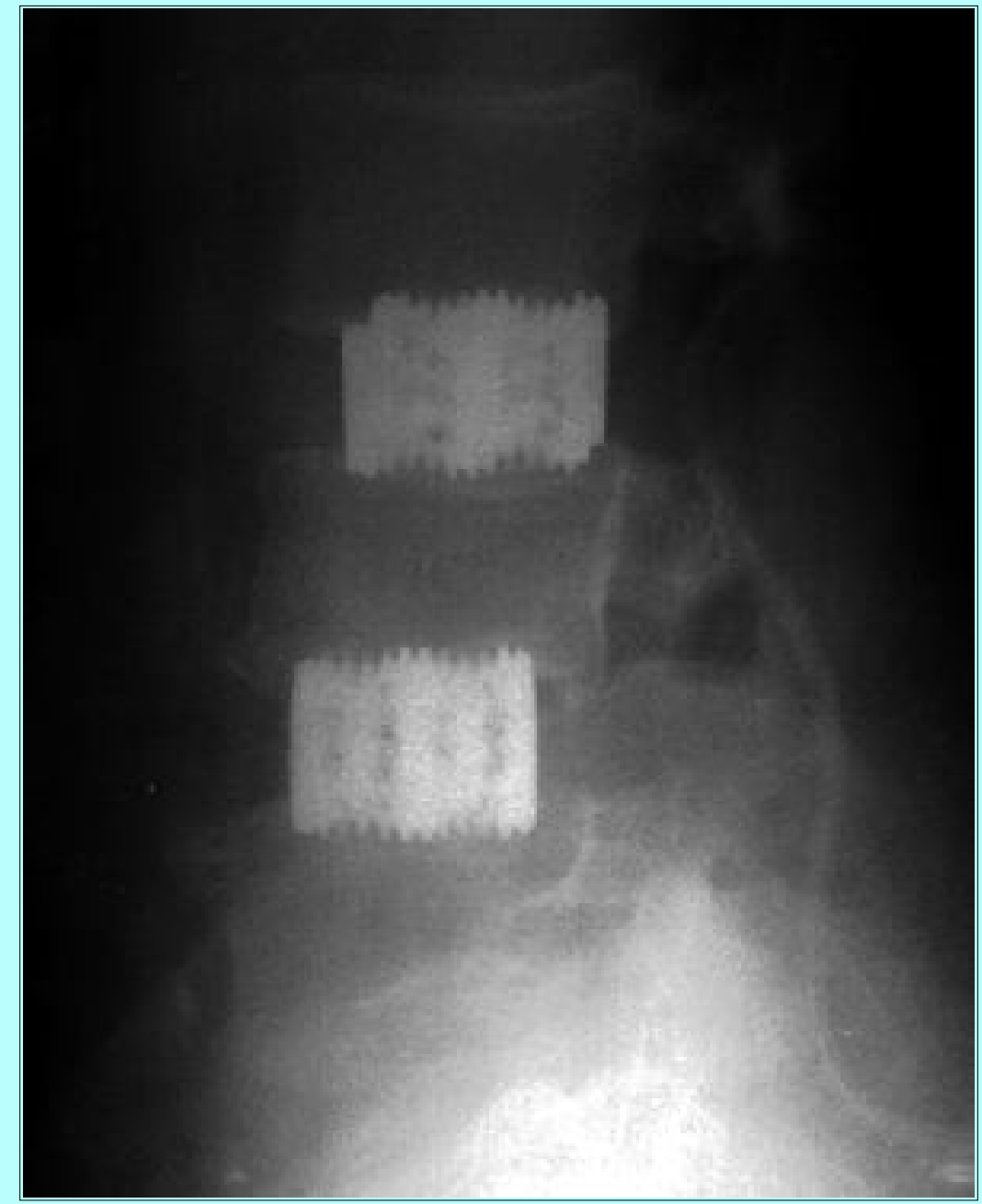

Fig. 3. Plain lateral lumbar radiograph demonstrating interbody grafts at L3-4 and L4-5 with titanium threaded cages. The patient is a 58-year-old man who presented with lumbar stenosis at L4-5 secondary to a large, recurrent disc herniation and ligamentous hypertrophy. The patient had undergone three previous lumbar operations.

\section{DISCUSSION}

The current surgical treatment of lumbar spinal stenosis is not entirely satisfactory. Several recent, well-designed studies underscore the need for more effective treatments and outcome measures.[18,39,40,51,68-70] Katz and associates[39] prospectively studied 194 patients treated with decompressive laminectomy for degenerative lumbar stenosis and reported that $22 \%$ of patients were somewhat or very dissatisfied with the results of surgery 6 months postoperatively. McCullen, et al.,[50] reviewing 118 patients who underwent lumbar decompression for acquired spinal stenosis, reported 50\% good, $27 \%$ fair, and $23 \%$ poor outcomes with an overall reoperation rate of $9 \%$. Furthermore, preoperative spondylolisthesis as well as progressive postoperative slippage clearly predisposed to poor outcome. Tuite and coworkers[68,69] reviewed 119 patients treated by decompressive lumbar laminectomy and found $66 \%$ good outcomes and $34 \%$ bad outcomes with a $15 \%$ reoperation rate. They 
also reported that surgical levels undergoing laminectomy were significantly more likely to develop progressive spinal deformity, including progressive spondylolisthesis, disc space angulation, and decreased disc space height. Herno and associates[27] reported 7- and 13-year follow-up intervals in 108 patients with lumbar canal stenosis treated with decompressive laminectomy and found good-to-excellent outcomes in $67 \%$ and $69 \%$, respectively. Caputy and Luessenhop[11] reported a $16 \%$ incidence of recurrent stenosis in 100 patients with degenerative stenosis treated by decompressive surgery. Silvers and associates[66] reviewed the long-term outcomes of 258 consecutive patients treated by means of decompressive laminectomies and reported only $64 \%$ pain relief and $56 \%$ return to normal activity rates. In 1992, Turner and associates[70] attempted a metaanalysis of the literature evaluating the effects of surgery for lumbar stenosis and reported an average of 64\% good-to-excellent outcomes. In 1991, Katz and associates[40] reviewed 88 consecutive patients treated with decompressive laminectomy and concluded that the long-term outcome for lumbar stenosis was less favorable than had previously been reported in the literature. They reported an $18 \%$ reoperation rate with $43 \%$ of all patients meeting the criteria for poor outcome. Hopp and Tsou[30] reviewed 344 patients surgically treated for spinal stenosis and reported a $17 \%$ reoperation rate due to postdecompression lumbar instability. Recently, Fox and colleagues[22] retrospectively evaluated 124 patients with degenerative lumbar stenosis treated with and without concomitant arthrodesis and reported better outcomes in patients treated with fusion.

Feffer, et al.,[21] compared two groups of patients with stenosis secondary to degenerative spondylolisthesis and found that patients undergoing decompression and fusion had more favorable outcomes than those treated with decompression alone. Herkowitz and Kurz[26] prospectively studied 50 patients with spinal stenosis associated with degenerative lumbar spondylolisthesis. They compared decompressive laminectomy alone versus decompression with intertransverse process fusion and found significantly better relief of back and lower-extremity pain in the latter group (44\% vs. $96 \%$, respectively), despite a pseudarthrosis rate of $36 \%$ in the fusion group. Furthermore, patients treated with decompression alone reported significantly more residual pain. Increased spondylolisthesis was noted postoperatively in $28 \%$ of patients treated with arthrodesis and in $96 \%$ of patients treated with decompression alone. Mardjetko and associates[48] completed a metaanalysis of the literature from 1970 to 1993 addressing the treatment of stenosis due to degenerative lumbar spondylolisthesis. These authors reported significantly poorer results in patients treated with decompression alone (70\% success rate) compared with patients who underwent fusion with and without instrumentation (86\% and $90 \%$ success rates, respectively).

Several factors appear to predispose patients with lumbar stenosis to poor outcomes. Numerous studies have implicated degenerative spondylolisthesis as a poor prognostic indicator.[9,26,30,36,42,50,61,65,68,69,73] Several authors have reported less favorable outcomes in women, $[9,19,27,34,50,65,68,69]$ younger patients, $[32,64,67,73]$ and patients undergoing repeated lumbar surgery.[15,28,52,61,72] Patient characteristics that warrant the consideration of arthrodesis (PLIF) in addition to decompression are listed in Table 1. 
spondyolisthesis (>0 $\mathrm{mm}$ slippage)

spinal instability (>2 $\mathrm{mm}$ motion on dynamic radiographs)

postdecompression stenosis

posttusion adjacent-le vel stenosis

younger age ( $<60$ yrs)

no complicating medical conditions (osteoporosis, diabetes mellitus)

In an effort to reduce poor outcomes and recurrent stenosis, some surgeons have attempted to identify a subgroup of patients with lumbar stenosis who would benefit from spinal arthrodesis. $[9,18,21,26,30,49,50,52]$ Spinal fusion, PLIF in particular, is technically more demanding to perform than decompressive surgery. Potential long-term consequences of segmental fusion, notably accelerated adjacent-level degeneration, must be further investigated and characterized. The higher operative morbidity rate and initial cost associated with arthrodesis warrant careful patient screening and appropriate selection of a high-risk population that would ultimately benefit from this procedure. Future prospective studies using standardized outcome measures with careful patient selection and long-term follow-up review are necessary to evaluate specific preoperative characteristics of patients with lumbar stenosis who would benefit from arthrodesis compared with decompression alone.

\section{CONCLUSIONS}

The pathogenesis of lumbar spinal stenosis is multifactorial. Intuitively, no single procedure can be successfully applied to treat such a diverse diagnostic entity. Using conventional decompressive surgery alone, there are relatively high failure (30-40\%) and reoperation (10-20\%) rates. The judicious application of PLIF, using strict patient selection criteria, has the potential to raise the overall success rate of operative intervention in the treatment of lumbar stenosis to a more acceptable level. There is a subgroup of high-risk patients in whom the spine is unstable preoperatively or becomes destabilized following decompression who would benefit from an initial fusion procedure. Therapeutic success would be significantly improved if this subgroup could be identified on the basis of preoperative characteristics. Treatment planning in each individual case should encompass such factors as the predominant site of neural compression (canal, lateral recess, or foramen) causing clinical symptoms; the predominant pathological process (bone encroachment, ligamentous hypertrophy, spondylolisthesis, buckling annulus/herniated disc) leading to neural compression; and high-risk factors (age, sex, underlying medical condition, previous surgery, spinal stability, and preoperative slippage). Posterior lumbar interbody fusion should be considered in complex cases of lumbar stenosis, most notably in younger, female patients with postlaminectomy stenosis or stenosis associated with spondylolisthesis.

\section{References}

1. Alexander E Jr: Significance of the small lumbar spinal canal: cauda equina compression syndromes due to spondylosis. Part 5: Achondroplasia. J Neurosurg 31: 513-519, 1968

2. Amundsen T, Weber H, Lilleas F, et al: Lumbar spinal stenosis. Clinical and radiologic features. Spine 20:1178-1186, 1995

3. Arnoldi CC, Brodsky AE, Cauchoix J, et al: Lumbar spinal stenosis and nerve root entrapment syndromes. Definition and classification. Clin Orthop 115:4-5, 1976 
4. Asano S, Kaneda K, Umehara S, et al: The mechanical properties of the human L4-5 functional spinal unit during cyclic loading. The structural effects of the posterior elements. Spine 17:1343-1352, 1992

5. Atlas SJ, Deyo RA, Keller RB, et al: The Maine Lumbar Spine Study, Part III. 1-year outcomes of surgical and nonsurgical management of lumbar spinal stenosis. Spine 21:1787-1795, 1996

6. Branch CL, Branch CL Jr: Posterior lumbar interbody fusion: the keystone technique, in Lin PM, Gill K (eds): Lumbar Interbody Fusion. Rockville, MD: Aspen, 1989, pp 211-219

7. Branch CL Jr: The case for posterior lumbar interbody fusion. Clin Neurosurg 43:252-267, 1996 8. Branch CL Jr: Posterior lumbar interbody fusion, in Hardy RW Jr (ed): Lumbar Disc Disease, ed 2. New York: Raven Press, 1993, pp 187-200

9. Bridwell KH, Sedgewick TA, O'Brien MF, et al: The role of fusion and instrumentation in the treatment of degenerative spondylolisthesis with spinal stenosis. J Spinal Disord 6:461-472, 1993

10. Brodsky AE: Post-laminectomy and post-fusion stenosis of the lumbar spine. Clin Orthop 115:130-139, 1976

11. Caputy AJ, Lussenhop AJ: Long-term evaluation of decompressive surgery for degenerative lumbar stenosis. J Neurosurg 77:669-676, 1992

12. Cauchoix J, Benoist M, Chassaing V: Degenerative spondylolisthesis. Clin Orthop 115:122-129, 1976

13. Cautilli RA: Theoretical superiority of PLIF, in Lin PM (ed): Posterior Lumbar Interbody Fusion. Springfield, IL: Charles C Thomas, 1982, p 82

14. Chen D, Fay LA, Lok J, et al: Increasing neuroforaminal volume by anterior interbody distraction in degenerative lumbar spine. Spine 20:74-79, 1995

15. Choudhury AR, Taylor JC: Occult lumbar spinal stenosis. J Neurol Neurosurg Psychiatry 40:506-510, 1977

16. Cloward RB: Modification of PLIF for spinal stenosis, in Lin PM (ed): Posterior Lumbar Interbody Fusion. Springfield, IL: Charles C Thomas, 1982, p 219

17. Deyo RA, Ciol MA, Cherkin DC, et al: Lumbar spinal fusion. A cohort study of complications, reoperations, and resource use in the Medicare population. Spine 18:1463-1470, 1993

18. diPierro CG, Helm GA, Shaffrey CI, et al: Treatment of lumbar spinal stenosis by extensive unilateral decompression and contralateral autologous bone fusion: operative technique and results. $\mathbf{J}$ Neurosurg 84:166-173, 1996

19. Epstein JA: Diagnosis and treatment of painful neurological disorders caused by spondylosis of the lumbar spine. J Neurosurg 17:991-1001, 1960

20. Esses SI, Natout N, Kip P: Posterior interbody arthrodesis with a fibular strut graft in spondylolisthesis. J Bone Joint Surg (Am) 77:172-176, 1995

21. Feffer HL, Wiesel SW, Cuckler JM, et al: Degenerative spondylolisthesis. To fuse or not to fuse. 
Spine 10:287-289, 1985

22. Fox MW, Onofrio BM, Hanssen AD: Clinical outcomes and radiological instability following decompressive lumbar laminectomy for degenerative spinal stenosis: a comparison of patients undergoing concomitant arthrodesis versus decompression alone. J Neurosurg 85:793-802, 1996

23. Grob D, Humke T, Dvorak J: Degenerative lumbar spinal stenosis. Decompression with and without arthrodesis. J Bone Joint Surg (Am) 77:1036-1042, 1995

24. Grobler LJ, Robertson PA, Novotny JE, et al: Decompression for degenerative spondylolisthesis and spinal stenosis at L4-5. The effects on facet joint morphology. Spine 18:1475-1482, 1993

25. Hasegawa T, An HS, Haughton VM, et al: Lumbar foraminal stenosis: critical heights of the intervertebral discs and foramina. A cryotome study in cadavera. J Bone Joint Surg (Am) 77:32-38, 1995

26. Herkowitz HN, Kurz LT: Degenerative lumbar spondylolisthesis with spinal stenosis. A prospective study comparing decompression with decompression and intertransverse process arthrodesis. J Bone Joint Surg (Am) 73:802-808, 1991

27. Herno A, Airaksinen O, Saari T: Long-term results of surgical treatment of lumbar spinal stenosis. Spine 18:1471-1474, 1993

28. Herno A, Airaksinen O, Saari T, et al: Surgical results of lumbar spinal stenosis. A comparison of patients with or without previous back surgery. Spine 20:964-969, 1995

29. Herron LD, Trippi AC: L4-5 degenerative spondylolisthesis. The results of treatment by decompressive laminectomy without fusion. Spine 14:534-538, 1989

30. Hopp E, Tsou PM: Postdecompression lumbar instability. Clin Orthop 227:143-151, 1988

31. Hutter CG: Spinal stenosis and posterior lumbar interbody fusion. Clin Orthop 193:103-114, 1985

32. Iida Y, Kataoka O, Sho T, et al: Postoperative lumbar spinal instability occurring or progressing secondary to laminectomy. Spine 15:1186-1189, 1990

33. Jane JA Sr, Jane JA Jr, Helm GA, et al: Acquired lumbar spinal stenosis. Clin Neurosurg 43:275-299, 1996

34. Johnsson KE, Redlund-Johnell I, Uden A, et al: Preoperative and postoperative instability in lumbar spinal stenosis. Spine 14:591-593, 1989

35. Johnsson KE, Rosen I, Udén A: The natural course of lumbar spinal stenosis. Clin Orthop 279:82-86, 1992

36. Johnsson KE, Willner S, Johnsson K: Postoperative instability after decompression for lumbar spinal stenosis. Spine 11:107-110, 1986

37. Jones AA, McAfee PC, Robinson RA, et al: Failed arthrodesis of the spine for severe spondylolisthesis. Salvage by interbody arthrodesis. J Bone Joint Surg (Am) 70:25-30, 1988

38. Jones RA, Thompson JL: The narrow lumbar canal. A clinical and radiological review. J Bone Joint 
Surg (Br) 50:595-605, 1968

39. Katz JN, Lipson SJ, Brick GW, et al: Clinical correlates of patient satisfaction after laminectomy for degenerative lumbar spinal stenosis. Spine 20:1155-1160, 1995

40. Katz JN, Lipson SJ, Larson MG, et al: The outcome of decompressive laminectomy for degenerative lumbar stenosis. J Bone Joint Surg (Am) 73:809-816, 1991

41. Kirkaldy-Willis WH, Wedge JH, Yong-Hing K, et al: Pathology and pathogenesis of lumbar spondylosis and stenosis. Spine 3:319-328, 1978

42. Lee CK: Lumbar spinal instability (olisthesis) after extensive posterior spinal decompression. Spine 8:429-433, 1983

43. Lee CK, Rauschning W, Glenn W: Lateral lumbar spinal canal stenosis: classification, pathologic anatomy and surgical decompression. Spine 13:313-320, 1988

44. Lin PM: Application of PLIF in lateral spinal stenosis, in Lin PM (ed): Posterior Lumbar Interbody Fusion. Springfield, IL: Charles C Thomas, 1982, p 178

45. Lin PM: Internal decompression for multiple levels of lumbar spinal stenosis: a technical note. Neurosurgery 11:546-549, 1982

46. Lin PM, Cautilli RA, Joyce MF: Posterior lumbar interbody fusion. Clin Orthop 180:154-168, 1983 47. Lorenz M, Patwardhan A, Vanderby R Jr: Load-bearing characteristics of lumbar facets in normal and surgically altered spinal segments. Spine 8:122-130, 1983

48. Mardjetko SM, Connolly PJ, Shott S: Degenerative lumbar spondylolisthesis. A meta-analysis of the literature 1970-1993. Spine 19 (Suppl 20):2256S-2265S, 1994

49. Markwalder TM: Surgical management of neurogenic claudication in 100 patients with lumbar spinal stenosis due to degenerative spondylolisthesis. Acta Neurochir 120:136-142, 1993

50. McCullen GM, Bernini PM, Bernstein SH, et al: Clinical and roentgenographic results of decompression for lumbar spinal stenosis. J Spinal Disord 7:380-387, 1994

51. Nakai O, Ookawa A, Yamaura I: Long-term roentgenographic and functional changes in patients who were treated with wide fenestration for central lumbar stenosis. J Bone Joint Surg (Am) 73:1184-1191, 1991

52. Nasca RJ: Rationale for spinal fusion in lumbar spinal stenosis. Spine 14:451-454, 1989

53. Nasca RJ: Surgical management of lumbar spinal stenosis. Spine 12: 809-816, 1987

54. Onel D, Sari H, Donmez C: Lumbar spinal stenosis: clinical/radiologic therapeutic evaluation in 145 patients. Conservative treatment or surgical intervention? Spine 18:291-298, 1993

55. Posner I, White AA III, Edwards WT, et al: A biomechanical analysis of the clinical stability of the lumbar and lumbosacral spine. Spine 7:374-389, 1982

56. Postacchini F, Cinotti G: Bone regrowth after surgical decompression for lumbar spinal stenosis. J 
Bone Joint Surg (Br) 74:862-869, 1992

57. Postacchini F, Cinotti G, Perugia D, et al: The surgical treatment of central lumbar stenosis. Multiple laminotomy compared with total laminectomy. J Bone Joint Surg (Br) 75:386-392, 1993

58. Robertson PA, Grobler LJ, Novotny JE, et al: Postoperative spondylolisthesis at L4-5. The role of facet joint morphology. Spine 18:1483-1490, 1993

59. Schlegel JD, Champine J, Taylor MS, et al: The role of distraction in improving the space available in the lumbar stenotic canal and foramen. Spine 19:2041-2047, 1994

60. Schlegel KF, Pon A: The biomechanics of posterior lumbar interbody fusion (PLIF) in spondylolisthesis. Clin Orthop 193:115-119, 1985

61. Schnee CL, Freese A, Ansell LV: Outcome analysis for adults with spondylolisthesis treated with posterolateral fusion and transpedicular screw fixation. J Neurosurg 86:56-63, 1997

62. Sharma M, Langrana NA, Rodriguez J: Role of ligaments and facets in lumbar spinal stability. Spine 20:887-900, 1995

63. Sheldon JJ, Russin LA, Gargano FP: Lumbar spinal stenosis. Radiographic diagnosis with special reference to transverse axial tomography. Clin Orthop 115:53-67, 1976

64. Shenkin HA, Hash CJ: Spondylolisthesis after multiple bilateral laminectomies and facetectomies for lumbar spondylosis. Follow-up review. J Neurosurg 50:45-47, 1979

65. Sienkiewicz PJ, Flatley TJ: Postoperative spondylolisthesis. Clin Orthop 221:172-180, 1987

66. Silvers HR, Lewis PJ, Asch HL: Decompressive lumbar laminectomy for spinal stenosis. J Neurosurg 78:695-701, 1993

67. Tile M, McNeil SR, Zarins RK, et al: Spinal stenosis. Results of treatment. Clin Orthop 115:104-108, 1976

68. Tuite GF, Doran SE, Stern JD, et al: Outcome after laminectomy for lumbar spinal stenosis. Part II: Radiographic changes and clinical correlations. J Neurosurg 81:707-715, 1994

69. Tuite GF, Stern JD, Doran SE, et al: Outcome after laminectomy for lumbar spinal stenosis. Part I: Clinical correlations. J Neurosurg 81:699-706, 1994

70. Turner JA, Ersek M, Herron L, et al: Surgery for lumbar spinal stenosis. Attempted meta-analysis of the literature. Spine 17:1-8, 1992

71. Weatherley CR, Prickett CF, O'Brien JP: Discogenic pain persisting despite solid posterior fusion. J Bone Joint Surg (Br) 68:142-143, 1986

72. Weinstein PR: Anatomy of the lumbar spine, in Hardy RW Jr (ed): Lumbar Disc Disease, ed 2. New York: Raven Press, 1993, pp 5-13

73. Wiltse LL, Kirkaldy-Willis WH, McIvor GW: The treatment of spinal stenosis. Clin Orthop 115:83-91, 1976 
74. Yong-Hing K, Kirkaldy-Willis WH: The pathophysiology of degenerative disease of the lumbar spine. Orthop Clin North Am 14:491-504, 1983

75. Yoshida M, Shima K, Taniguchi Y, et al: Hypertrophied ligamentum flavum in lumbar spinal canal stenosis: pathogenesis and morphologic and immunohistochemical observation. Spine 17:1353-1360, 1992

Manuscript received May 14, 1997.

Accepted in final form July 15, 1997.

Address reprint requests to: Domagoj Coric, M.D., Department of Neurosurgery, Bowman Gray School of Medicine, Wake Forest University, Medical Center Boulevard, Winston-Salem, North Carolina 27157-1029. 